\title{
Microbial Degradation of Gasoline in Soil: Effect of Season of Sampling
}

\begin{abstract}
In cases where fire debris contains soil, microorganisms can rapidly and irreversibly alter the chemical composition of any ignitable liquid residue that may be present. In this study, differences in microbial degradation due to the season in which the sample is collected was examined. Soil samples were collected from the same site during Fall, Winter, Spring and Summer and the degradation of gasoline was monitored over 30 days. Predominant viable bacterial populations enumerated using real-time PCR and reverse transcriptase polymerase chain reaction (RT-PCR) enumeration revealed the predominant viable bacterial genera to be Alcaligenes, Bacillus, and Flavobacterium. Overall, the compounds most vulnerable to microbial degradation are the $n$-alkanes, followed by the mono-substituted alkylbenzenes (e.g., toluene, ethylbenzene, propylbenzene and isopropylbenzene). Benzaldehyde (a degradation product of toluene) was also identified as a marker for the extent of biodegradation. Ultimately, it was determined that soil collected during an unusually hot and dry summer exhibited the least degradation with little to no change in gasoline for up to 4 days, readily detectable n-alkanes for up to 7 days and relatively high levels of resilient compounds such as o-xylene, $p$-xylene and 1,3,5-trimethylbenzene. These results demonstrate, however, that prompt preservation and/or analysis of soil evidence is required in order to properly classify an ignitable liquid residue.
\end{abstract}

This is the author's manuscript of the article published in final edited form as:

Turner, D. A., Pichtel, J., Rodenas, Y., McKillip, J., \& Goodpaster, J. V. (2015). Microbial degradation of gasoline in soil: Effect of season of sampling. Forensic science international, 251, 69-76.

http://dx.doi.org/10.1016/j.forsciint.2015.03.013 


\section{Introduction}

The forensic implications of microbial degradation of ignitable liquids in soil have been studied by various authors [1-8]. However, the influence of season of year on microbial degradation of ignitable liquids that are relevant to fire investigations has not been reported. As discussed elsewhere [6], populations of soil bacteria vary based on soil chemical and physical characteristics including $\mathrm{pH}$, concentrations of $\mathrm{N}$ and $\mathrm{P}$, organic matter content, and soil texture. In turn, soil chemical characteristics vary based on season of the year, and may therefore influence microbial populations and activities throughout the year. Varying populations and activities of soil microorganisms could profoundly impact the degree of microbial degradation observed in fire debris samples containing soil.

Microbial degradation of normal alkanes (e.g., decane) and lesser substituted alkylbenzenes (e.g., toluene, ethylbenzene, propylbenzene) occurs rapidly in soil while more highly substituted alkylbenzenes (e.g., 1,2,4-trimethylbenzene) and highly branched alkanes are less susceptible to microbial degradation [4-7]. The deliberate use of microorganisms to treat hydrocarbon-contaminated soil is well-understood by environmental scientists [9-20]; however, the processes that govern microbial activity in samples intended for forensic analysis are less understood. As soil chemical and physical properties vary, heterotrophic microorganisms will be impacted, leading to variations in observed differences in the effects of microbial degradation on gasoline and other ignitable liquids.

The objectives of the present study were to assess the biodegradation of an ignitable liquid that is commonly encountered in fire debris from an incendiary fire (i.e., 87 octane gasoline). Specific objectives include: (1) analysis of GC/MS data from gasoline added to soil 
over four seasons; (2) identification and quantification of microbial populations present in the study soil; and (3) investigation of possible correlations between soil properties with microbial decomposition of added hydrocarbons.

\section{Materials and Methods}

Soil Chemical Analyses

Soil material was obtained from a residential property (Miamian sandy clay) in central Indiana. Soil material was collected during four seasons (January, April, July, October) from the surface $0-20 \mathrm{~cm}$ using a stainless steel sampling probe. Soil samples were composited in the field, and air-dried and sieved ( $<2 \mathrm{~mm}$ mesh) in the laboratory.

Particle size distribution of the samples was determined using the hydrometer method [18]. Total organic carbon (TOC) and total nitrogen (N) were analyzed on a Perkin Elmer Series II CHNS/O Analyzer 2400 (Shelton, CT). Acetanilide was the standard used. Soil pH was determined using a 1:2 (w:v) solids:deionized water slurry with an AB15 Accumet pH meter.

Soil nitrate $\left(\mathrm{NO}_{3}\right)$ concentrations were measured using Szechrome reagents [21] in a BioteK PowerWave XS2 microassay system. Ammonium $\left(\mathrm{NH}_{4}\right)$ concentrations were determined by the method of Sims et al. which uses a modified indophenol blue technique [22]. The method was adapted for the BioteK PowerWave system. Extractable $P$ was determined by the Bray-1 method [23]. Soil $\mathrm{K}$ was extracted with neutral $1.0 \mathrm{M}$ ammonium acetate and analyzed using atomic emission spectrophotometry (Perkin Elmer AAnalyst 2000). Extractable metal (Cd, $\mathrm{Cr}, \mathrm{Fe}, \mathrm{Zn}, \mathrm{Pb}$ ) concentrations were determined by extraction with 5 mM DTPA (diethylenetriaminepentaacetic acid) with $10 \mathrm{mM} \mathrm{CaCl}_{2}, \mathrm{pH}$ adjusted to 7.3. Briefly, the method involved mechanical shaking (120 osc./min. for $2 \mathrm{~h}$ ) of $5 \mathrm{~g}$ soil with $25 \mathrm{ml}$ of $5 \mathrm{mM}$ DTPA in acid- 
washed Nalgene ${ }^{\circledR}$ bottles. The suspension was filtered through Whatman No. 2 filter paper and analyzed for $\mathrm{Cd}, \mathrm{Cr}$, Fe, $\mathrm{Zn}$ and $\mathrm{Pb}$ using flame atomic absorption spectrophotometry (Perkin Elmer AAnalyst 2000). For the above analyses, there were four replicates of each sample.

\section{Soil Microbiological Analyses}

Populations of total culturable bacteria were determined in each soil sample using the standard plate count technique [24] on Plate Count Agar (Teknova, Hollister, CA). Soil-borne actinomycetes were enumerated on Actinomycete Isolation Agar (Sigma-Aldrich, St. Louis, MO) and yeasts and molds were quantified using Sabouraud Dextrose agar (Fisher Scientific,

Waltham, MA). For each sampling date, colony counts were averaged (six replicates) following $48 \mathrm{~h}$ incubation of all inoculated plates. Colony counts were assessed using exponential and log transformations via SigmaStat 3.5 (Point Richmond, CA). Control and experimental groups were compared using a one-tailed Student's t test, and different media combinations were compared using one-way ANOVA (Minitab 16, State College, PA) followed by Student-Neuman-Keuls post hoc analysis and two-factor factorial analysis using SAS (SAS Institute, Cary, NC). Data were considered significantly different at $p<0.05$.

For the genetic identification of bacteria, DNA was obtained from 3-5 g soil samples using a commercial system (MoBIO, Solana Beach, CA) and quantified spectrophotometrically. Real-time PCR was carried out in a Smart Cycler II (Cepheid, Sunnyvale, CA). Extracted DNA (1 $\mu g$ ) was added to real-time SYBR Green ${ }^{\mathrm{TM}}$ Supermix (Quanta Biosciences, Gaithersburg, MD); a no-template contamination control was analyzed for each sample/primer set, as well as positive control specimens consisting of genomic DNA from ATCC (Manassas, VA) type strains or other reference strains of Acinetobacter, Alcaligenes, Arthrobacter, Bacillus, Burkholderia, 
and Flavobacterium. All PCR primers were designed with the software analysis options available through the National Center for Biotechnology Information Basic Local Alignment Search Tool (NCBI BLAST) (www.ncbi.nlm.nih.gov/BLAST), which allows for sequences to be screened for nonspecific annealing frequencies and non-target homology determination. Internal standard primer targets in each case were the highly conserved prokaryotic gyrase subunit B gene, gyrB [25]. Primer sequences and PCR cycling regime were used as described by Turner et al., 2014 [8]. Each primer pair was tested on all non-target strains to ensure appropriate specificity and eliminate the appearance of a false-positive amplification signal. Cycling conditions were 10 min. at $95^{\circ} \mathrm{C}$, followed by 40 three-step cycles of $15 \mathrm{~s}$ at $95^{\circ} \mathrm{C}, 1 \mathrm{~min}$. at $55^{\circ} \mathrm{C}$ and $1 \mathrm{~min}$ at $72^{\circ} \mathrm{C}$, with fluorescence acquisition monitored at the end of each cycle. In order to enumerate viable cell density with high sensitivity, reverse transcriptase PCR was subsequently performed on whole RNA extracted from $5 \mathrm{~g}$ soil of each sampling date using Trizol (Invitrogen, Grand Island, NY). RNA was standardized to $1 \mu \mathrm{g}$ following DNAse-I treatment and subjected to cDNA synthesis and amplification using the qScript ${ }^{\mathrm{TM}}$ One-Step SYBR ${ }^{\circledR}$ Green qRT-PCR Kit (Quantas Biosciences) and genus-specific primers. Viable cell densities were ascertained using the calculations described below for DNA targets and compared by soil type and season.

Standard curves to determine number of copies of target genomes (and mRNA) for each bacterial genus were constructed using quantified bacterial templates obtained from each reference strain 1:10 serially diluted in nuclease-free water to $10^{-6}$ (each diluted in triplicate) and subjected to amplification as described above. Bacterial template concentrations were converted to amplicon (PCR product) copies by multiplying the mean grams of DNA purified for each set of extraction replicates by $6.02 \times 10^{23}$, and dividing that product by the product of the 
respective amplicon length in base pairs X 650 Daltons. Resulting plots depict the number of amplicon copies as a function of respective cycle threshold $(\mathrm{Ct})$ values.

\section{Microbial Degradation Studies}

One hundred grams of each soil was spiked with 20 microliters of commercial unleaded gasoline (87 octane) and then physically mixed in a clean, non-sterile quart-size paint can. The samples were sealed and stored for $0,2,4,7,11,15,22$, and 30 days. On the specified day, samples were extracted using a passive headspace adsorption-elution method that has been previously described and is routinely performed in forensic science laboratories [8]. Samples were analyzed by GC-MS (Agilent 6890 gas chromatograph with an Agilent 5975 mass spectrometer) using a method for fire debris analysis. This method has been previously described in [8]. Briefly, the method utilized a DB-5 column (30 $\mathrm{m} \times 0.25 \mathrm{~mm} \times 0.25 \mu \mathrm{m})$, helium carrier gas at $1 \mathrm{~mL} / \mathrm{min}$ and an inlet temperature of $250{ }^{\circ} \mathrm{C}$. The oven program started at $40{ }^{\circ} \mathrm{C}$ for $3 \mathrm{~min}$, ramped to $280^{\circ} \mathrm{C}$ at $10^{\circ} \mathrm{C} / \mathrm{min}$, and held at $280^{\circ} \mathrm{C}$ for $3 \mathrm{~min}$. The scan range of the MS was $\mathrm{m} / \mathrm{z} 40-\mathrm{m} / \mathrm{z} 300$.

\section{Data Analysis}

The compounds of interest to this study included the normal alkanes from $C_{7}$ to $C_{15}$ as well as the mono-, di- and tri-substituted benzenes. Each component was identified based on comparison of its retention time and mass spectrum to authentic standards and the National Institute of Standards and Technology mass spectral database. Summed Extracted Ion Profiles (EIPs) were generated corresponding to characteristic fragments of $n$-alkanes $(\mathrm{m} / \mathrm{z} 57,71,85$, and 99) and aromatics ( $\mathrm{m} / \mathrm{z} 91,105$, and 119). The peak areas in each of the EIPs were generated using the Xcaliber data analysis software (Thermo Scientific). 
A particularly powerful method for analyzing complex data sets is Principal Component Analysis (PCA). The software used to perform PCA was XLSTAT (AddinSoft), an add-in for Microsoft Excel. Principal Components Analysis (PCA) can be used to elucidate trends in the data while taking into account any correlations between the variables [8, 26-29]. Prior to conducting PCA, the data was normalized and autoscaled to correct for variation in peak areas due to compound concentration as well as variability in peak areas due to differences in the variance of the ions that were used to construct EIPs. Then, using the same approach that has been previously described [8], a biplot was constructed that plotted the observations according to their scores along PC 1 and PC2. Therefore, observations that are very similar (e.g., replicates from the same soil) will be in proximity and observations that are very different (e.g., day 0 versus day 30 samples) would be well separated. In addition, a biplot plots the variables in terms of their relationship with the principal components and one another. Variables that are positively correlated (e.g., alkanes of similar length) will be in proximity on a biplot and variables that are negatively correlated (e.g., a readily degraded compound versus a resilient compound) will appear opposite one another.

\section{Results and Discussion}

\section{Soil Chemical Analyses}

The purpose of soil chemical and physical characterization was two-fold; first, the data establishes a baseline set of properties of the soil under study. Second, soil analysis helps to determine whether changes in the properties of the soil may have affected microbial activity. The physical and chemical properties of the soil are summarized in Table 1. The soil was sandy clay. This texture is fairly typical for much of the northern two-thirds of the state of Indiana, 
which is overlain by substantial deposits of till from the Wisconsin glacial epoch [30]. Soil pH was 6.3. Total soil $\mathrm{N}$ measured $0.23 \mathrm{mg} / \mathrm{kg}$; soluble $\mathrm{NO}_{3}$ and $\mathrm{NH}_{4}$ levels were 40.4 and 3.0 $\mathrm{mg} / \mathrm{kg}$, respectively. Soil TOC was $1.0 \%$. Levels of extractable $\mathrm{Cd}, \mathrm{Cr}$, Fe and $\mathrm{Zn}$ were all within range for non-contaminated soils.

Table 1. Selected chemical and physical properties of the study soil.

\begin{tabular}{cc}
\hline Parameter & Value \\
\hline $\mathrm{pH}$ & $6.3 \pm 0.07$ \\
Total $\mathrm{N}, \%$ & 0.23 \\
$\mathrm{NO}_{3}{ }^{-}, \mathrm{mg} / \mathrm{kg}$ & $40.4+3.4$ \\
$\mathrm{NH}_{4}{ }^{+}, \mathrm{mg} / \mathrm{kg}$ & $3.0 \pm 0.1$ \\
$\mathrm{TOC}^{*}, \%$ & $1.0 \pm 0.1$ \\
Bray- $1 \mathrm{P}, \mathrm{mg} / \mathrm{kg}$ & $137.3 \pm 4.7$ \\
Extractable $\mathrm{K}, \mathrm{mg} / \mathrm{kg}$ & $154.5 \pm 30.6$
\end{tabular}

Extractable metals, $\mathrm{mg} / \mathrm{kg}$

$\begin{array}{lc}\mathrm{Cd} & 0.43 \pm 0.036 \\ \mathrm{Cr} & 0.16 \pm 0.01 \\ \mathrm{Fe} & 39.5 \pm 2.8 \\ \mathrm{Zn} & 24.2 \pm 4.7 \\ \mathrm{~Pb} & 12.7 \pm 0.5\end{array}$

Particle size analysis

\begin{tabular}{cc} 
Sand, \% & $46.8 \pm 1.3$ \\
Silt, \% & $12.7 \pm 0.5$ \\
Clay, \% & $40.5 \pm 1.1$ \\
Texture & sandy clay \\
Structure & granular \\
\hline lorganic carbon. &
\end{tabular}

$* \mathrm{TOC}=$ total organic carbon.

Trends in Soil $p H$ and N Species

Soil $\mathrm{pH}$ values remained relatively constant over the year, ranging from 6.2 to 6.5 .

Soluble $\mathrm{NO}_{3}$ concentrations were lowest during winter $(15.9 \mathrm{mg} / \mathrm{kg})$, increasing through spring and summer to a maximum value of $40.4 \mathrm{mg} / \mathrm{kg}$ in fall. This increase is ascribed to nitrate release during the growing season following application of slow-release fertilizers and 
decomposition of organic matter [31]. Similarly, $\mathrm{NH}_{4}$ values were lowest during winter through summer, reaching a maximum of $3 \mathrm{mg} / \mathrm{kg}$ in fall.

\section{Soil Microbiological Analyses}

Enumeration of soilborne bacteria may be completed using the traditional culture-based methods familiar to microbiologists (i.e., standard plate count), using appropriately selective media for the target group(s) of interest. Our results from this approach (Table 2) revealed no significant differences in total bacteria or fungi counts across the soil by season $(p>0.05)$.

Table 2. Values shown represent mean colony counts (and SD) of eight replicates, none of which were significantly ( $p>0.05)$ different across the sampling times. Plate count agar for total chemoheterotrophic bacteria; $\mathrm{ACT}$ =actinomycete agar, for soilborne actinomycetes; SDA = Sabouraud dextrose agar for total molds and yeasts [8].

\begin{tabular}{|c|c|}
\hline Media & Mean Colony Counts (SD) \\
\hline Plate Count Agar & $2.54 \times 10^{5}\left(4.5 \times 10^{2}\right)$ \\
\hline ACT & $7.1 \times 10^{5}\left(2.2 \times 10^{2}\right)$ \\
\hline SDA & $4.48 \times 10^{4}\left(8.94 \times 10^{2}\right)$ \\
\hline
\end{tabular}

However, these findings do not necessarily reflect the relative levels of viable target microorganisms in the soils, since recovered densities of each group may not be in proportion to their relative numbers in the natural soil communities. Moreover, only a fraction of the viable microorganisms in an environmental sample are recoverable on artificial media. Thus, a more sensitive measure of these genera was performed that targets genomic DNA from select bacteria of interest based on a precedent for bioremediation or breakdown of chemical adulterants in soil communities. This DNA-based approach was real-time PCR targeting conserved ribosomal DNA sequences that allow for total genome equivalents (copy number) for each genus to be determined. Our results revealed an actual density of each genus markedly higher than that seen in the culture-based experiments (Table 3). 
Table 3. qPCR-based enumeration of genome copies per gram of soil from each bacterial genus in this study. Values represent the mean values from triplicate samples analyzed using SYBR Green-based standard curves as described in Materials and Methods. From Turner et al., 2014 [8].

\begin{tabular}{|c|c|}
\hline Bacterial Genus & Genome copies per gram \\
\hline Acinetobacter & $3.12 \times 10^{16}$ \\
\hline Alcaligenes & $2.37 \times 10^{20}$ \\
\hline Arthrobacter & $1.636 \times 10^{13}$ \\
\hline Bacillus & $5.12 \times 10^{14}$ \\
\hline Flavobacterium & $4.53 \times 10^{10}$ \\
\hline Pseudomonas & $1.682 \times 10^{14}$ \\
\hline
\end{tabular}

Using standard curves constructed by a type strain of each genus, we determined how many genome equivalents were detectable across each season. Over all seasons, the average value did not differ significantly ( $p>0.05$ ) with Acinetobacter spp. and Alcaligenes faecalis consistently yielding the highest detectable genomic DNA copies (Table 3).

PCR detection of rDNA sequences was used to quantify total genome equivalents for representative bacterial genera with a prior history in the literature of potential for chemical adulterant metabolism in soil environments [36-39]. Acinetobacter, Alcaligenes, Arthrobacter, Bacillus, Flavobacterium, and Pseudomonas genera were analyzed here by qPCR using genus-specific PCR primers and standard curves generated with ATCC type strain DNA [8]. The calculated total genome equivalents of each bacterial genus is shown in Table 3 . These qPCR results reveal that in all soil treatments, Alcaligenes spp. were consistently detectable at significantly higher levels $(p<0.05)$ than any other genus analyzed, and that the values detected (both here and for the RNA analyses described below) did not differ significantly seasonally. $A$. faecalis has been reported to degrade the chlorinated insecticide endosulfan, found routinely in many soil types, water (and as residue on foods). This ubiquitous chemical has been in 
widespread use for many years and is readily transported through watersheds and soil microcosms [42], so the particularly high relative copy numbers here throughout all soil types and seasons suggests that this species has adapted unique tolerances to a variety of potential chemical pollutants. Other studies have shown that $A$. faecalis metabolizes aromatic hydrocarbons and other similar chemical adulterants in soil [43]. Many of these studies, or similar ones not cited, represent artificial systems containing previously sterile soil seeded with known strains at defined densities, rather than assessing naturally-occurring endogenous strains as was done here. The six bacterial genera selected for analysis here was based on dominant populations seen in soils of this region from past work in our laboratory. Calculated genome copies of each bacterial group using rDNA-specific PCR revealed densities many orders of magnitude above recovered bacterial densities on plate count agar, an observation attributable to the fact that DNA-based PCR detects template copies from both viable bacterial targets and from dead cells accumulated in the soil biomass. The latter is certainly contributing artificially to the actual viable, actively metabolizing cell density of each target genus, which is the rationale for RNA-based PCR. By quantifying target mRNA from each species of interest (separately), one may accurately (and sensitively) enumerate those bacteria most directly offering potential for bioremediation.

Table 4 reveals that Alcaligenes in fact remains at very high viable cell levels compared to the other genera, overshadowed only by Bacillus spp. and perhaps Flavobacterium.

Table 4. Determination of specific mRNA transcript copies per gram of soil using qRT-PCR, to ascertain viable cell densities from each bacterial genus in this study. Numbers reported are mean densities from triplicate analyses using SYBR Green-based standard curves as described in Materials and Methods and in Turner et al., 2014 [8].

\begin{tabular}{|l|l|}
\hline Bacterial Genus & mRNA transcript copies per gram \\
\hline
\end{tabular}




\begin{tabular}{|c|c|}
\hline Acinetobacter & $1.16 \times 10^{2}$ \\
\hline Alcaligenes & $5.56 \times 10^{13}$ \\
\hline Arthrobacter & $5.32 \times 10^{12}$ \\
\hline Bacillus & $3.06 \times 10^{17}$ \\
\hline Flavobacterium & $7.68 \times 10^{11}$ \\
\hline Pseudomonas & $3.00 \times 10^{5}$ \\
\hline
\end{tabular}

Since the target gene (mRNA) in this PCR assay was the conserved 16S rDNA segment of each genus, one may conclude that some of the variation seen in these values may be due to the presence of rRNA-encoding genes in multiple copy numbers in certain bacterial species (and that the respective copy number, as here, may not always be known). However, these RT-PCR data indicate that in fact Alcaligenes would make a logical choice for further, more specific studies, related to exactly which biodegradation pathways would be prospective targets to control rate and type of chemical adulterant removal in contaminated soils.

\section{Microbial Degradation Studies}

There were significant losses of all $n$-alkanes in the gasoline samples (see Figure 1 ). Degradation was evident in the chromatograms after 7 days and the majority of the alkanes were significantly depleted by 15 days. All alkanes were essentially eliminated after 30 days in all samples. Note that the early-eluting peaks that remain in the later chromatograms are due to volatile aldehydes that are typically observed in all soils at low levels.[4-6]

The soil collected during the summer was not as active with regards to the biodegradation of alkanes (Figure 1). For example, alkanes could be extracted from this soil in relatively high amounts even after 7 days. The summer of the study year was unusually dry and 
hot which may have inhibited microbial activity. In contrast, the aliphatic hydrocarbons were degraded at a faster rate in the winter sampling, with essentially no peaks evident after 7 days.

Biologically-mediated degradation of aromatic hydrocarbons resulted in a significant reduction of all alkyl benzenes, but not to the same extent as for the alkane fraction. In particular, five $C_{3}$-alkylbenzenes (3-ethyltoluene, 4-ethyltoluene, 1,3,5-trimethylbenzene, 2ethyltoluene, and 1,2,4-trimethylbenzene) must be identified in a fire debris sample in order to classify an ignitable liquid residue as gasoline per consensus standards for fire debris analysis (ASTM E1618). Furthermore, these compounds must be present in ratios similar to that of a gasoline standard. The portions of the chromatograms that contain six peaks from $\mathrm{C}_{3}-$ alkylbenzenes are shown in Figure 2. Of these compounds, the only mono-substituted benzene (propylbenzene) was rapidly and significantly reduced in all samples regardless of time of collection. This agrees with prior studies that show that biodegradation is more pronounced in mono-substituted benzenes such as toluene, ethylbenzene and propylbenzene.

Soils collected in the Fall and Winter exhibited a significant drop in intensity of all the alkylbenzenes over 30 days. Note that the y-axes of the chromatograms in Figure 2 have been normalized to the largest peak in the chromatogram. Hence, the overall loss of alkylbenzenes leads to a steady decline in the signal-to-noise ratio as well as growing interferences from soil matrix compounds such as camphene. However, the overall distribution (as reflected in relative peak heights) was well-preserved, which would still allow for the identification of gasoline. Soils collected in the Spring show significant distortion in the chromatogram with a noticeable reversal in the peak height ratio of 3-ethyltoluene and 1,2,4-trimethylbenzene over 30 days. The gasoline chromatograms also had increasing interference from benzaldehyde as 
degradation continued. Benzaldehyde is known to be an oxidative product of the biodegradation of toluene and, in this project, served as a convenient marker for biodegradation.[32-34]

The biplot generated from PCA for soil samples collected in the Fall is shown in Figure 3. The observations from day 0 samples are projected in the upper right quadrant in proximity to variables for compounds that are readily degraded, such as the normal alkanes from $C_{8}$ to $C_{11}$ and ethyl-, propyl-, and isopropylbenzene. There is a substantial change in gasoline composition after 2 days, with the observations in proximity to more resilient compounds such as xylenes, ethyltoluenes, and trimethylbenzenes. After 4 days, the observations move away from all gasoline compounds and by 22 days, the samples are closely associated only with benzaldehyde.

The biplot generated from PCA for soil samples collected in the winter is shown in Figure 4. The observations from day 0 samples are projected at the top of the $y$-axis (F2) in proximity to variables for readily degraded compounds such $C_{14}-C_{15} n$-alkanes and toluene, ethyl benzene, propyl benzene. There is a substantial change in gasoline composition after 2 days; observations for day 2 and day 4 samples are in roximity to readily degraded compounds such as $C_{7}$ through $C_{13} n$-alkanes as well as more resilient aromatics such as xylene, ethyltoluenes, and $\mathrm{C}_{3}$-alkylbenzenes. However, between 7 and 30 days, the observations move away from all gasoline compounds and towards benzaldehyde.

The biplot generated from PCA for soil samples collected in the Spring is shown in Figure 5. The observations from day 0 samples are projected in the upper right quadrant, in proximity to variables for readily degraded compounds such as $C_{9}-C_{15} n$-alkanes and toluene. There is a 
substantial change in gasoline composition after 2 days and again after 4 days with the observations in proximity to more resilient aromatics such as xylene, ethyltoluenes, and $\mathrm{C}_{3}$ alkylbenzenes. After 4 days, the observations move away from all gasoline compounds and, by day 22 , the samples are closely associated only with benzaldehyde.

Lastly, the biplot generated from PCA for soil samples collected in Summer is shown in Figure 6 . The data set is unusual in that observations from day 0 , day 2 and day 4 samples are all projected near the negative end of the x-axis (PC1) in proximity to readily degraded compounds such as $\mathrm{C}_{7}-\mathrm{C}_{11} n$-alkanes, toluene, ethyl-, propyl-, and isopropylbenzene. There is a substantial change in the composition after 7 days as exhibited by the large shift in the projection of these samples. However, even after 30 days, samples from the Summer soil remain closely associated with the more resilient aromatics such as 0 -xylene, $p$-xylene and 1,3,5-trimethylbenzene. This is in agreement with the data shown in Figures 1 and 2, and shows that the Summer soil samples were less active and the gasoline was not as significantly affected by microbial degradation.

\section{Conclusions}

The findings presented here demonstrate that $n$-alkanes and mono-substituted benzenes in gasoline are the most vulnerable to microbial decomposition, and di- and trisubstituted benzenes are the least vulnerable. We identified a biodegradation product (benzaldehyde) that is known to originate from toluene, a component of gasoline. Benzaldehyde was useful when it was included in the PCA analysis as it served as a clear marker for the extent of biodegradation in a sample. In general, the soils collected during Fall, Winter and Spring caused substantial microbial degradation, with noticeable changes occurring after 
only two days. The summer soil sample, however, was clearly less active. Both alkanes and alkyl benzenes remained intact for longer periods on the Summer soil, which is attributed to the extremely hot and dry conditions during that sampling period. 


\section{References}

[1] Mann DC, Gresham WR. Microbial Degradation of Gasoline in Soil. J Forensic Sci. 1990;35:913-21.

[2] Kirkbride KP, Yap SM, Andrews S, Pigou PE, Klass G, Dinan AC, et al. Microbial Degradation of Petroleum Hydrocarbons: Implications for Arson Residue Analysis. J Forensic Sci. 1992;37:1585-98.

[3] Chalmers D, Yan SX, Cassista A, Hrynchuk R, Sandercock PMI. Degradation of Gasoline, Barbecue Starter Fluid, and Diesel Fuel by Microbial Action in Soil. Can Soc Forens J. 2001;34:49-62.

[4] Turner DA, Goodpaster JV. The effects of microbial degradation on ignitable liquids. Anal Bioanal Chem. 2009;394:363-71.

[5] Turner DA, Goodpaster JV. The effect of microbial degradation on the chromatographic profiles of tiki torch fuel, lamp oil, and turpentine. J Forensic Sci. 2011;56:984-7.

[6] Turner DA, Goodpaster JV. Comparing the effects of weathering and microbial degradation on gasoline using principal components analysis. J Forensic Sci. 2012;57:64-9.

[7] Turner DA, Goodpaster JV. The effects of season and soil type on microbial degradation of gasoline residues from incendiary devices. Anal Bioanal Chem. 2013;405:1593-9.

[8] Turner DA, Pichtel J, Rodenas Y, McKillip J, Goodpaster JV. Microbial degradation of gasoline in soil: comparison by soil type. J Biorem Biodegrad. 2014;5:1000216/1-/7, 7 pp.

[9] Crawford RL, Crawford DL. Bioremediation: Principles and Applications. In: Lynch J, editor. Biotechnology Research Series. Cambridge, Grat Britain: Press Syndicate of the University of Cambridge; 1996. p. 400.

[10] Heipieper HJ. Bioremediation of Soils Contaminated with Aromatic Compounds. In: Series NS, editor. Earth and Environmental Sciences. Dordrecht, The Netherlands: Springer; 2007. p. 130. [11] Hernandez BS, Koh SC, Chial M, Focht DD. Terpene-utilizing isolates and their relevance to enhanced biotransformation of polychlorinated biphenyls in soil. Biodegradation. 1997;8:153-8. 
[12] Huang H, Larter S. Biodegradation of petroleum in subsurface geological reservoirs. In: Ollivier B, Magot M, editors. Petroleum Microbiology. Washington, DC: ASM; 2005. p. 30.

[13] Magot M. Petroleum Microbiology. In: Ollivier B, Magot M, editors. Indigenous microbial communities in oil fields. Washington DC: ASM; 2005.

[14] Mars AE, Gorissen JPL, vandenBeld I, Eggink G. Bioconversion of limonene to increased concentrations of perillic acid by Pseudomonas putida GS1 in a fed-batch reactor. Appl Microbiol Biotechnol. 2001;56:101-7.

[15] McLoughlin E, Rhodes AH, Owen SM, Semple KT. Biogenic volatile organic compounds as a potential stimulator for organic contaminant degradation by soil microorganisms. Environmental Pollution. 2009;157:86-94.

[16] Misra G, Pavlostathis SG. Biodegradation kinetics of monoterpenes in liquid and soil-slurry systems. Appl Microbiol Biotechnol. 1997;47:572-7.

[17] Sasek V, Glaser JA, Baveye P. The Utilization of Bioremediation to Reduce Soil Contamination: Problems and Solutions. In: Series NS, editor. Earth and Environmental Sciences. Dordrecht, The Netherlands: Kluwer Academic Publishers; 2003. p. 417.

[18] Singh A, Ward OP. Biodegradation and Bioremediation. In: Varma A, editor. Soil Biology. Berlin, Germany: Springer-Verlag; 2004. p. 309.

[19] vanAgteren $\mathrm{MH}$, Keuning S, Janssen DB. Handbook on Biodegradation and Biological Treatment of Hazardous Organic Compounds. Dordrecht, The Netherlands: Kluwer Academic Publishers; 1998.

[20] Duarte da Cunha C, Gomes FL, Selma. Gasoline biodegradation in different soil microcosms. Brazlian Journal of Microbiology. 2000;31:45-9.

[21] Polysciences I. Szechrome Reagents. Technical Data Sheet 239. Warrington, PA(no date).

[22] Sims GK, Ellsworth TR, Mulvaney RL. Microscale determination of inorganic nitrogen in water and soil extracts. Communications in Soil Science and Plant Analysis. 1995;26:303-16. 
[23] Olsen SR, Sommers LE. Phosphorus. In: Page AL, Miller RL, Keeney DR, editors. Methods of Soil Analysis, Part 2. Madison, WI: American Society of Agronomy; 1982. p. 403-30.

[24] Cappuccino JG, Sherman N. Experiment 53: Microbial populations in soil: Enumeration. Microbiology: A Laboratory Manual. New York, NY: Addison Wesley Longman; 1998.

[25] Watanabe K. Microorganisms relevant to bioremediation. Curr Opin Biotechnol. 2001;12:237-41.

[26] Tan B, Hardy JK, Snavely RE. Accelerant classification by gas chromatography/mass spectrometry and multivariate pattern recognition. Analytica Chimica Acta. 2000;422:37-46.

[27] Doble P, Sandercock M, DuPasquier E, Petocz P, Roux C, Dawson M. Classification of premium and regular gasoline by gas chromatography/mass spectrometry, principal component analysis and artificial neural networks. Forensic Sci Int. 2003;132:26-39.

[28] Pierce KM, Hope JL, Johnson KJ, Wright BW, Synovec RE. Classification of gasoline data obtained by gas chromatography using a piecewise alignment algorithm combined with feature selection and principal component analysis. Journal of Chromatography A. 2005;1096:101-10.

[29] Marshall L, Mcllory JW, McGuffin VL, Smith RW. Association and discrimination of diesel fuels using chemometric procedures. Anal Bioanal Chem. 2009;394:2049-59.

[30] U.S. Department of Health and Human Services. Chemical Information Review Document for NButylbenzenesulfonamide. 2010.

[31] Brady NC, Weil RR. The Nature and Properties of Soils. 14th ed: Prentice Hall; 2007.

[32] Seyfried B, Glod G, Schocher R, Tschech A, Zeyer J. Initial reactions in the anaerobic oxidation of toluene and m-xylene by denitrifying bacteria. Applied and Environmental Microbiology. 1994;60:404752.

[33] Altenschmidt U, Fuchs G. Anaerobic toluene oxidation to benzyl alcohol and benzaldehyde in a denitrifying Pseudomonas strain. Journal of Bacteriology. 1992;174:4860-2. 
[34] Lovley DR, Lonergan DJ. Anaerobic Oxidation of Toluene, Phenol, and p-Cresol by the Dissimilatory Iron-Reducing Organism, GS-15. Applied and Environmental Microbiology. 1990;56:1858-64.

[35] Vanbroekhoven K, Ryngaert A, Wattiau P, Mot R, Springael D (2004) Acinetobacter diversity in environmental samples assessed by $16 \mathrm{~S}$ rRNA gene PCR-DGGE fingerprinting. FEMS Microbiol Ecol 50: 37-50.

[36] Menn FM, Easter JP, Sayler GS (2008) Genetically Engineered Microorganisms and Bioremediation, in Biotechnology: Environmental Processes, Wiley, USA.

[37] Westerberg K, Elväng AM, Stackebrandt E, Jansson JK (2000) Arthrobacter chlorophenolicus sp. nov., a new species capable of degrading high concentrations of 4-chlorophenol. Int J Syst Evol Microbiol 50 Pt 6: 2083-2092.

[38] O'Loughlin EJ, Sims GK, Traina SJ (1999) Biodegradation of 2-methyl, 2-ethyl, and 2-hydroxypyridine by an Arthrobacter sp. isolated from subsurface sediment. Biodegradation 10: 93-104.

[39] McSpadden Gardener BB (2004) Ecology of Bacillus and Paenibacillus spp. in Agricultural Systems. Phytopathology 94: 1252-1258.

[40] Abdel-El-Haleen, D. (2003) Acinetobacter: environmental and biotechnological applications. African Journal of Biotechnology 2:71-74.

[41] Chin S.P., Ismail N.S., Al-Ashraf Abdullah A., \& Yahya A.R.M. (2010) Aerobic Degradation of Volatile Fatty Acids by Bacterial Strain Isolated from Rivers and Cow Farm in Malaysia. Journal of Bioremediation and Biodegradation 1:111. doi:10.4172/2155-6199.1000111.

[42] Kong, L., Zhu, S., Zhu, L., Xie, H., et al. 2013. Degradation of PCB in different soils by inoculated Alcaligenes xylosoxidans. Sci Total Environ 175: 275-285.

[43] O'Mahony M.M., Dobson A.D., Barnes J.D., \& Singleton I. (2006) The use of ozone in the remediation of polycyclic aromatic hydrocarbon contaminated soil. Chemosphere 63:307-14. 
Figure 1: The alkane profile for gasoline on residential soil in fall, winter, spring, and summer after 0, 2, 7, 15 and 30 days.

Figure 2: The aromatic profile of the $\mathrm{C}_{3}$-alkylbenzenes in gasoline on residential soil collected in the fall, winter, spring, and summer after $0,2,7,15$ and 30 days. Peaks: 1) propylbenzene, 2) 3-ethyltoluene, 3) 4-ethyltoluene, 4) 1,3,5-trimethylbenzene, 5) 2-ethyltoluene, 6) 1,2,4-trimethylbenzene

Figure 3: PCA biplot for the microbial degradation of gasoline on residential soil over 30 days for the Fall sampling. Soil samples are designated as " $F$ " for fall; number of days of degradation; and replicate number (e.g., F-4-1 is the first replicate from a sample aged 4 days on Fall sampling). The observations begin in the upper right quadrant and progress to the lower right quadrant over 30 days.

Figure 4: PCA biplot for the microbial degradation of gasoline on residential soil over 30 days for the Winter sampling. Soil samples are designated as "W" for winter; number of days of degradation; and replicate number (e.g., W-4-1 is the first replicate from a sample aged 4 days on Winter sampling). The observations begin at the positive end of the $y$-axis (PC2) and progress to the lower left quadrant over 30 days.

Figure 5: PCA biplot for the microbial degradation of gasoline on residential soil over 30 days for the Spring sampling. Soil samples are designated as "Sp" for Spring; number of days of degradation; and replicate number (e.g., $\mathrm{Sp}-4-1$ is the first replicate from a sample aged 4 days on Spring sampling). The observations begin in the upper right quadrant and progress to the lower left quadrant over 30 days.

Figure 6: PCA biplot for the microbial degradation of gasoline on soil over 30 days for the Summer sampling. Soil samples are designated as "Su" for summer; number of days of degradation; and replicate number (e.g., Su-4-1 is the first replicate from a sample aged 4 days on Summer sampling). The observations begin at the negative end of the $x$-axis (PC1) and progress to the lower right quadrant over the course of 30 days. 


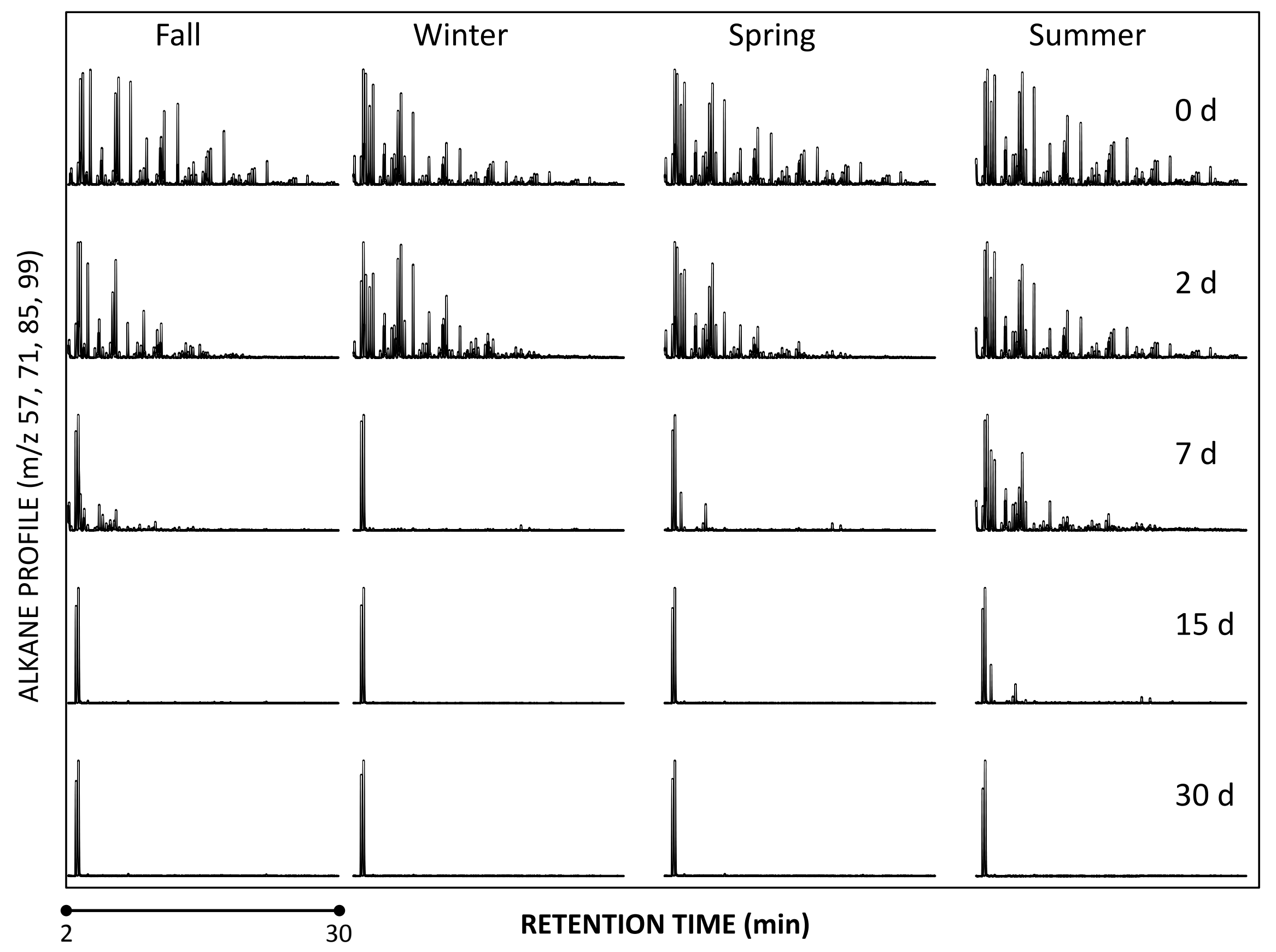




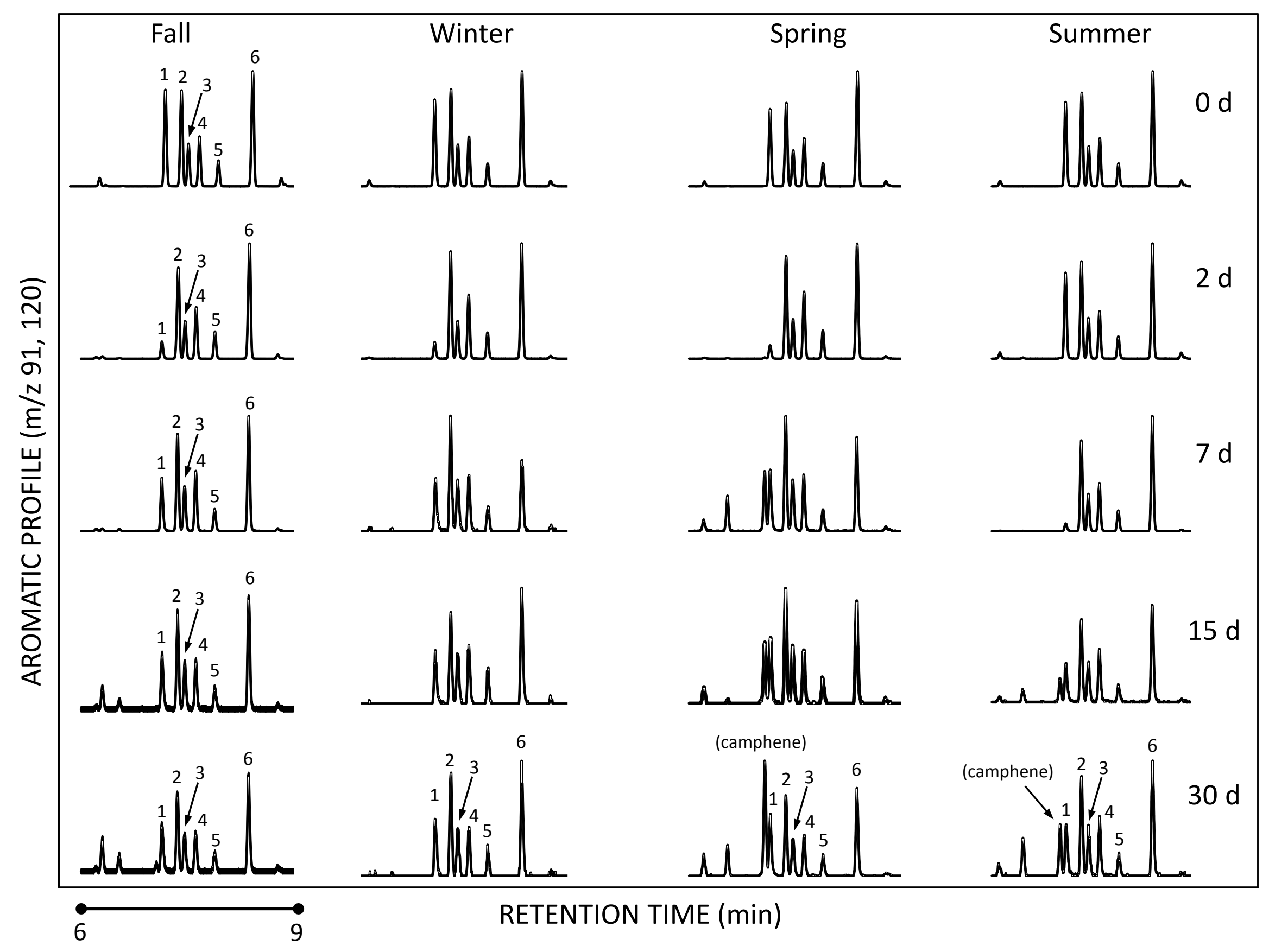


Biplot (axes F1 and F2: 63.90 \%)

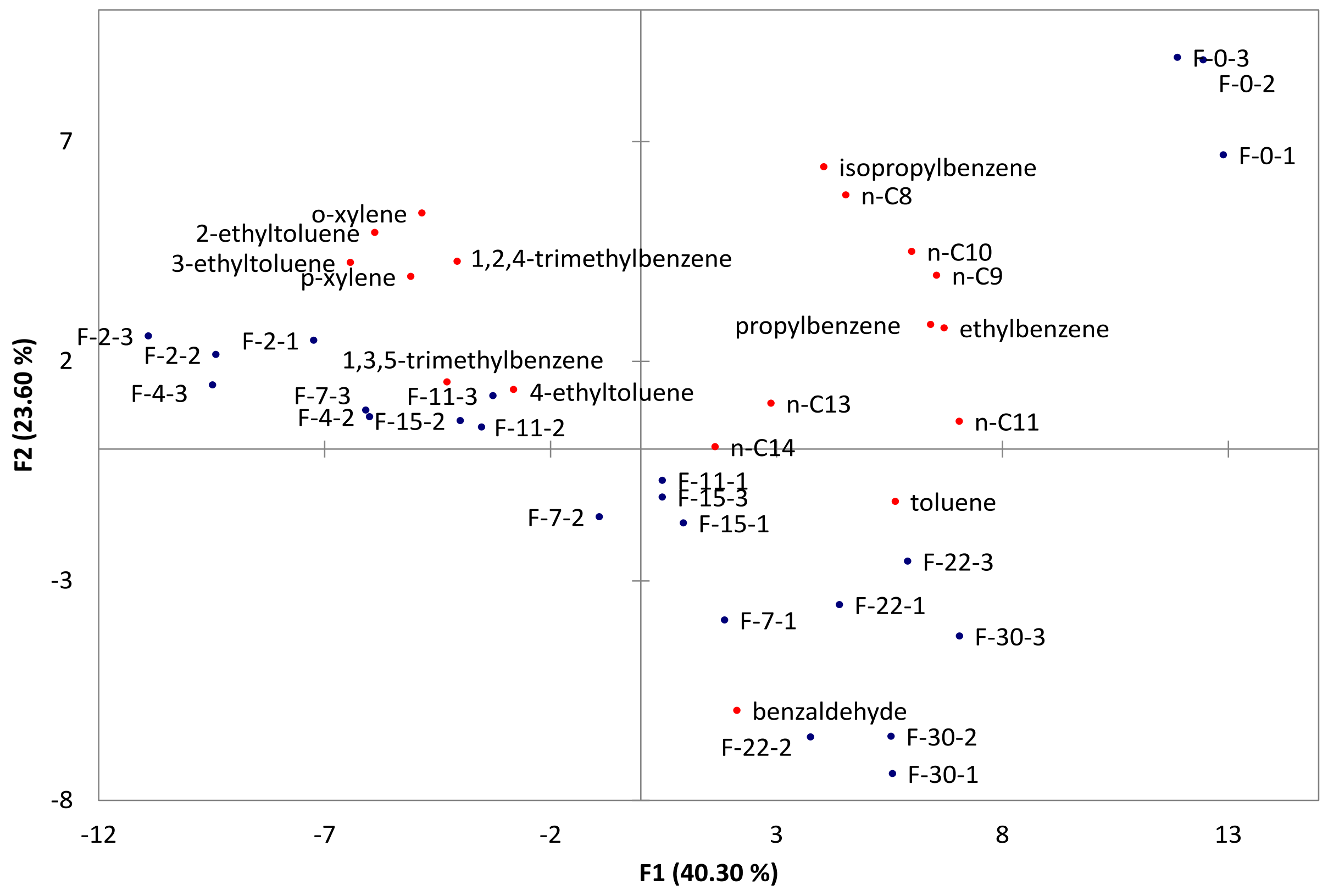




\section{Biplot (axes F1 and F2: 69.64 \%)}

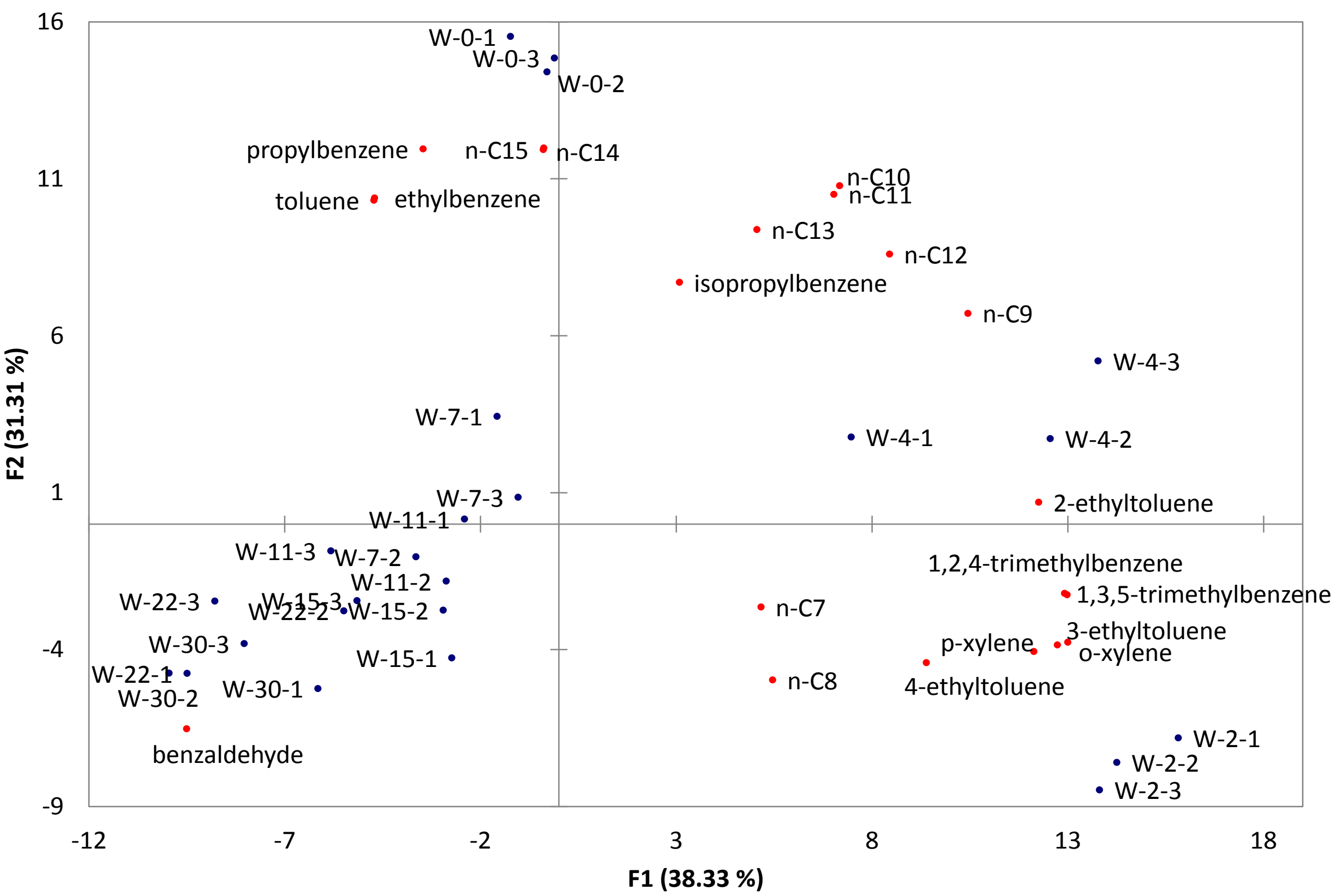


Biplot (axes F1 and F2: 61.85 \%)

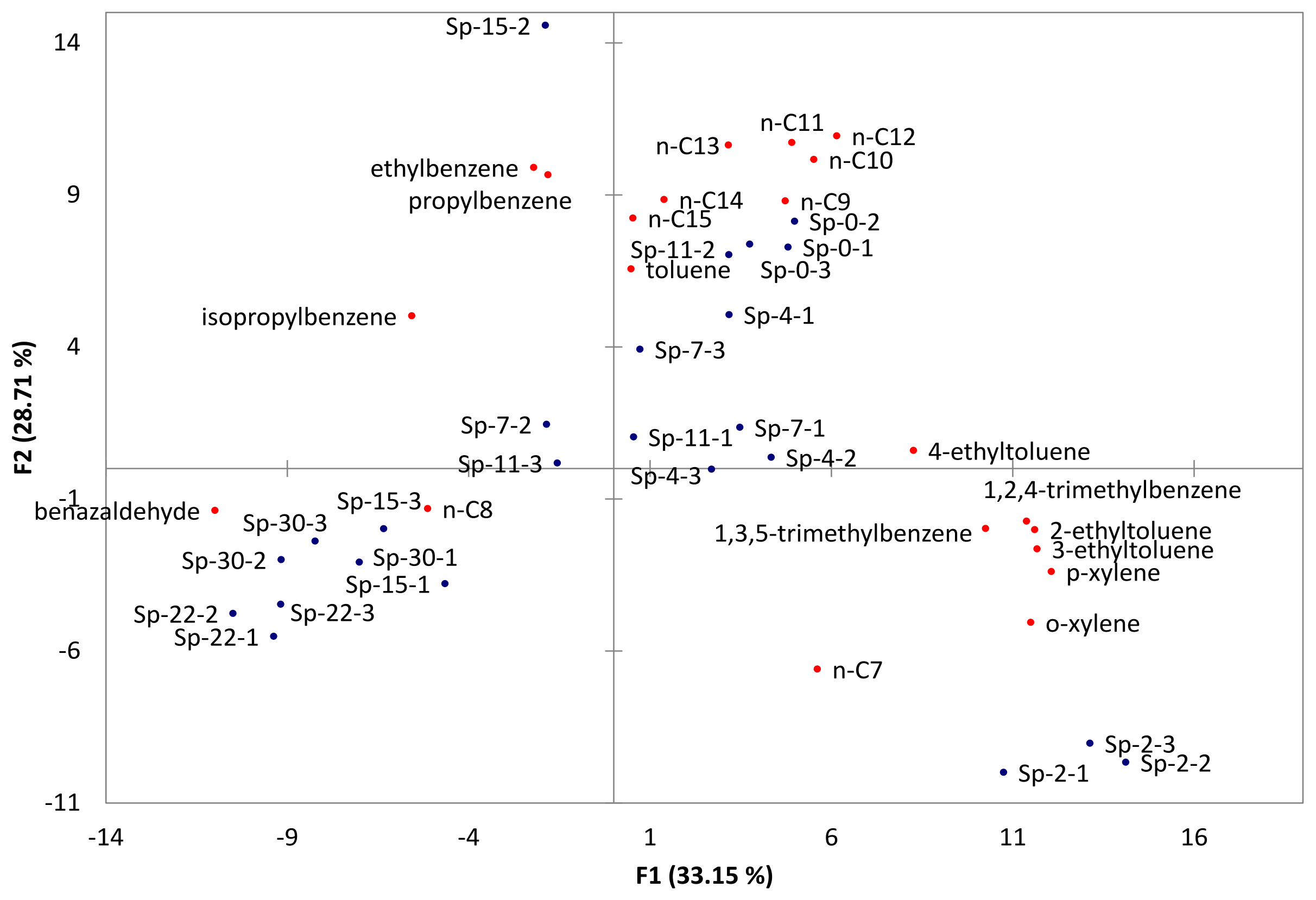


Biplot (axes F1 and F2: $71.75 \%$ )

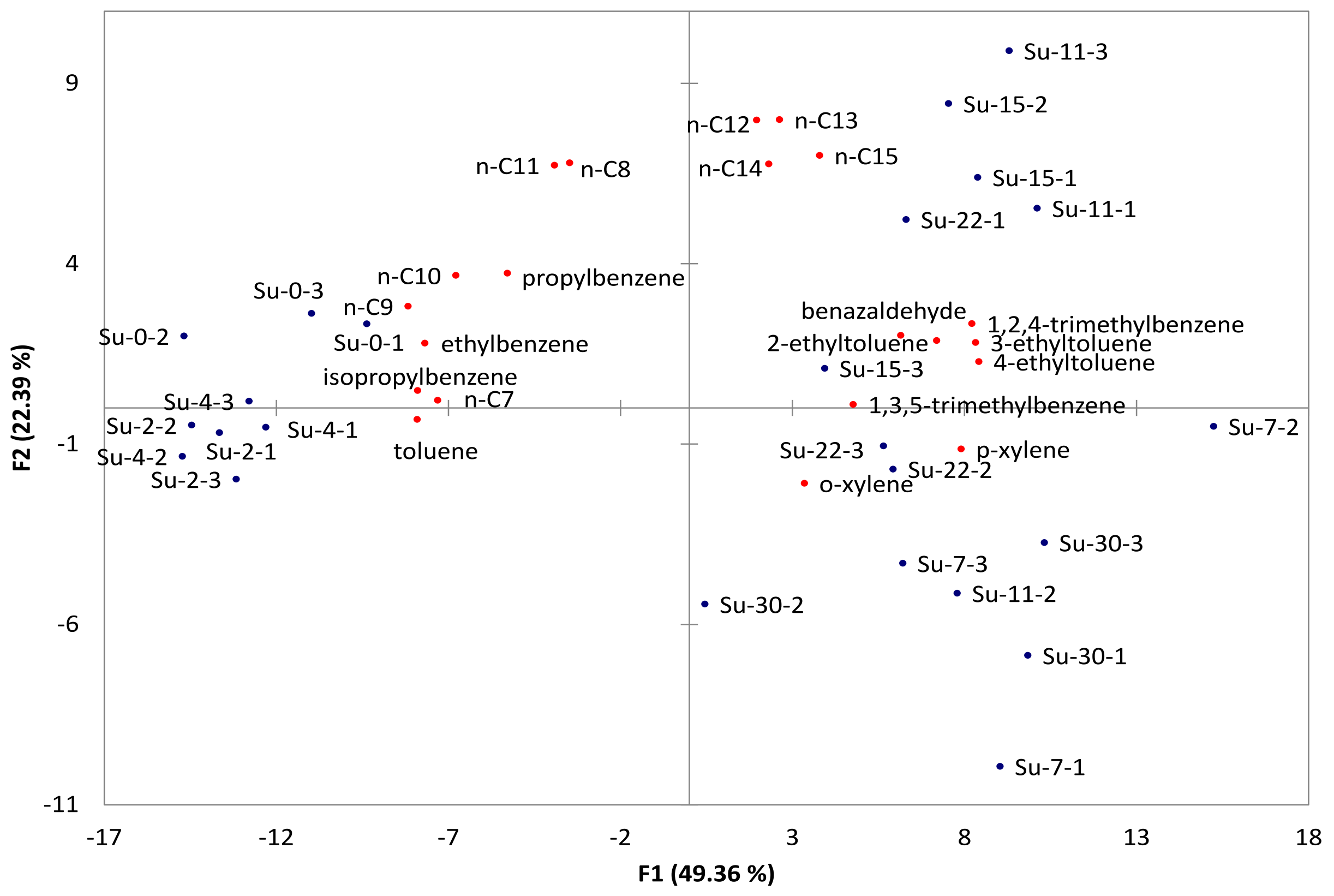

